\title{
EHealth Literacy in UK Teenagers and Young Adults: Exploration of Predictors and Factor Structure of the eHealth Literacy Scale (eHEALS)
}

Patricia Holch, BSc, PhD; Jordan R Marwood, BSc, MSc

Psychology Department, Leeds School of Social Sciences, Leeds Beckett University, Leeds, United Kingdom

\section{Corresponding Author:}

Patricia Holch, BSc, PhD

Psychology Department

Leeds School of Social Sciences

Leeds Beckett University

Room CL 815, Calverley Building

City Campus, Leeds Beckett University

Leeds, LS1 3HE

United Kingdom

Phone: 44011381 ext 24950

Email: t.holch@leedsbeckett.ac.uk

\section{Abstract}

Background: Increasingly, teenagers and young adults (TYAs) seek out health information online; however, it is not clear whether they possess electronic health (eHealth) literacy, defined as "the ability to select, appraise, and utilize good quality health information from the internet." A number of factors are included in the Lily model proposed by Norman and Skinner underpinning the development of eHealth literacy. It is important to understand which elements may influence the development of eHealth literacy in young people, as the current generation will continue to "Google it" when faced with a health problem throughout their lives.

Objective: The objectives of this study are to explore potential factors influencing young people's eHealth literacy and explore the underlying constructs of the eHealth Literacy Scale (eHEALS) in a population of UK university students.

Methods: A total of 188 undergraduate psychology students from a large UK University were recruited as an opportunity sample. Of these, $88.8 \%$ (167/188) of participants were female with a mean age of 20.13 (SD 2.16) years and the majority were White British (159/188, 84.6\%). Employing a cross-sectional design TYAs completed the following measures exploring eHealth literacy (eHEALS): Irrational Health Belief Scale; Newest Vital Sign (NVS), a measure of functional health literacy; Need for Cognition Scale, a preference for effortful cognitive activity; and General Self-Efficacy (GSE) Scale, exploring personal agency and confidence. The eHEALS was also subject to exploratory factor analysis (EFA), for which in addition to the total variance explained, the scree plot, eigenvalues, and factor loadings were assessed to verify the structure.

Results: eHEALS and GSE were significantly positively correlated $(r=0.28, P<.001)$ and hierarchical linear modeling revealed GSE as the significant predictor of scores on the eHEALS $\left(F_{1,186}=16.16, P<.001, R^{2}=0.08\right)$, accounting for $8.0 \%$ of the variance. Other notable relationships were GSE and need for cognition (NFC) were also positively correlated $(r=0.33, P<.001)$, and NFC and irrational health beliefs were significantly negatively correlated ( $r=-.14, P=.03)$. Using Spearman correlations, GSE and $\operatorname{NVS}\left(r_{\mathrm{s}}=0.14, P=.04\right)$ and NFC and NVS $\left(r_{\mathrm{s}}=0.19, P=.003\right)$ were positively correlated. An EFA revealed the scale to be stable and identified a 2 -factor structure related to information acquisition and information application.

Conclusions: This is the first study in the UK to explore relationships between these key variables and verify the structure of the eHEALS in a TYA population in the UK. The findings that self-efficacy has a major influence firmly consolidate its status as fundamental to the development of eHealth literacy. Future studies will explore the influence of body image and the development of eHealth literacy in more diverse TYA populations.

(JMIR Form Res 2020;4(9):e14450) doi: 10.2196/14450 


\section{KEYWORDS}

eHealth literacy; irrational health beliefs; predictors; self-efficacy; teenagers and young adults; need for cognition; exploratory factor analysis

\section{Introduction}

\section{Background}

Almost all young adults in the UK are shown to be recent internet users [1] with teenagers present online for over 6 hours a day [2]. Indeed, most young adults consider the internet a valid source of health information $[3,4]$ and compared with "digital immigrants," "digital natives" (ie, those who have grown up in the digital age) seek out more health information electronically [5]. While the internet has transformed and widened access to health information, there has been concern about the quality of electronic health (eHealth) resources [6,7] and indeed whether people can select good quality health information on the internet. Undoubtedly, increasing the health literacy of populations is now seen as essential and is fast becoming a global challenge [8]. In England, 15\% of adults are classed as functionally illiterate [9] and 32 million adults in the United States are unable to read [10]. However, successfully accessing eHealth resources goes beyond functional literacy skills and requires "eHealth literacy," defined as the ability to "seek out, find, evaluate and appraise, integrate, and apply what is gained in electronic environments toward solving a health problem" ([11], p. 2).

\section{Young People and eHealth Literacy}

Intuitively one would assume that young people as "digital natives" would be competent users of the technology they have been brought up with; however, this is not always the case [12]. Equally they are not always capable users of eHealth resources [13]. This lack of competency and fundamental concerns around the extent of misinformation in eHealth resources [14] have the potential to impact public health in terms of individual health outcomes and unnecessary burdens on health care systems [15]. Therefore, it is important to know whether young people can discern if the information gained from eHealth resources is of good quality and appropriate to their needs. To this end, Norman and Skinner [16] have developed a measure of perceived eHealth literacy - the "eHealth Literacy Scale" (eHEALS). Good reliability and validity from the eHEALS are demonstrated in young people in the United States [17] and the measure has been successfully translated into several languages [18-20]. Thus, if we are to successfully measure eHealth literacy, it is also important to understand factors that may influence the perceived ability of teenagers and young adults (TYAs) to successfully navigate internet-provided health resources. This is particularly crucial as this is the first generation to have grown up with access to eHealth resources and will continue to "Google it" when faced with a health problem throughout their lives. Therefore, it is important to gain a deeper understanding of what factors potentially influence eHealth literacy in young people. Norman and Skinner [11] propose that eHealth literacy is underpinned by a set of complex skills depicted by the 6-factor Lily model. The model proposes the following 6 overlapping literacies that determine and influence eHealth literacy: traditional literacy, health literacy, information literacy, scientific literacy, media literacy, and computer literacy. Here we explore putative variables which could enable the exploration of eHealth literacy and the 6-factor Lily model in young adults today.

\section{Potential Factors Influencing eHealth Literacy}

\section{Functional Health Literacy}

One of the fundamental variables underpinning the Lily model is functional health literacy (FHL; ie, the literacy and numeracy skills required to read and understand health information). FHL is an essential skill in navigating health information and pivotal to successful engagement with health resources over the internet. Recent studies have shown that there is a relationship between FHL and eHealth literacy; higher scores in FHL were correlated with higher scores on the eHEALS in a sample of Italian adults [21]. Until recently we have had few reliable and valid ways to measure FHL in the UK. However, the Newest Vital Sign (NVS), a new measure of FHL, has recently been adapted [22] and validated against the Test of Functional Health Literacy in Adults (TOFHLA) in the UK [23], thus enabling an exploration of a potential relationship between FHL and eHealth literacy in the TYA population in the UK.

\section{Need for Cognition}

Norman and Skinner cite Feuerstein [24] who describes media literacy as successful navigation for those who develop metacognitive reflective strategies to enable them to reflect, reason, and discern media information. As such, media literacy has been adopted as an important component of the Lily model. Although not all those who use the media have the same level of cognitive facility, we often differ in our willingness to engage in cognitive activity to aid our understanding. Need for cognition (NFC) is an individual difference which can be described as "people's tendency to engage in, and enjoy, effortful cognitive activity" ([25], p. 130). Those with high NFC enjoy problem solving, actively search for information, and reflect on the findings [26]. By contrast, those with low NFC avoid problem solving and rely on others to process and present information (eg, celebrities or powerful others). In terms of internet use, NFC is positively correlated with all internet activities involving cognitive thought [27], and also linked to cancer screening uptake such that matching health messages to information-processing styles improved mammography attendance at 6 months in high NFC women [28]. More recently NFC was explored in relation to eHealth literacy in US university students, establishing a positive relationship between high NFC and eHEALS scores, and showing those with high NFC scores would be more likely to seek out health information online [29]. Thus, it seems a natural progression to explore whether this relationship between NFC and eHEALS exists in a UK university sample. 


\section{Irrational Health Beliefs}

However, it is not only cognitive capacity which underpins success in processing and utilizing health information. Generally, it is assumed that health and scientific information are processed rationally. However, some (particularly people with anxiety) have "irrational health beliefs" (IHBs) which can be explained by the cognitive-behavioral model of hypochondriasis [30,31]. People with IHBs believe serious illness to be more prevalent than it is, believe fast action health input is imperative, and fear disastrous health outcomes (if not treated) [32]. This irrationality can have a dramatic influence on young peoples' information literacy and their use and interpretation of health information and decision making (eg, in not adequately responding to the real costs and benefits of alcohol consumption) [33]. Certainly, it was found that people with higher IHBs have poorer health and are less likely to adhere to treatments $[34,35]$. Clearly, this could be problematic for seeking health information via the internet and using this appropriately. Indeed, this "worried and wired" combination has recently been shown to be detrimental where individual levels of health anxiety have negatively influenced the relationship between online health information seeking and health care utilization [36]. Thus, in terms of influencing the health, science, and media literacy of young people, IHB is a concept worthy of study.

\section{Self-Efficacy}

Underpinning the previously mentioned components of the Lily model, Norman and Skinner state that electronic health literacy is born out of social cognitive theory proposed by Bandura [37], with self-efficacy (SE) being a major component [38]. SE is defined as "beliefs in one's capabilities to mobilize the motivation, cognitive resources, and courses of action needed to meet given situational demands" ([39], p. 408). High SE [40] is related to engaging and maintaining healthy behaviors, and is a key component of most major health models [41]. SE is viewed as the factor to bridge the intention-behavior gap, the most eagerly pursued link of health behavior change. SE is pivotal to seeking out information and acting appropriately on it via the internet and is likely to improve the likelihood of utilizing the resources successfully [42]. Therefore, measuring young people's general levels of self-efficacy (GSE) is an important factor to explore in relation to perceived eHealth literacy.

The putative factors we have reviewed here all relate to young people's experiences of help seeking via the internet and consequent health behavior. Further, these factors reflect the overlapping literacies of the Lily model proposed by Norman and Skinner [11], namely, health literacy, information literacy, scientific literacy, media literacy, and computer literacy.

With regard to the scale to measure eHealth literacy (eHEALS) [16], this been evaluated with young adults and baby boomers in the United States, whereas in the UK and New Zealand this has been evaluated only in the latter [43]. Therefore, it would be prudent to also conduct an exploratory construct analysis on the eHEALS in a UK TYA population.

\section{Aims}

The primary aim was to explore whether factors potentially underpinning the 6 facets of the Lily model [11] (including NVS [FHL], IHBs, NFC, and GSE) are associated with and are significant predictors of eHealth literacy in young people measured by the eHEALS [16].

A secondary aim was to explore the underlying constructs of the eHEALS using an exploratory factor analysis (EFA) in a sample of university students in the UK.

\section{Methods}

\section{Participants}

Participants $(n=188)$ were undergraduate psychology students from a UK University recruited via opportunity sampling in research methods sessions. Of these, 167 participants were female (88.8\%), with a mean age of 20.13 (SD 2.16) years. The majority of participants identified their ethnicity as White British $159 / 188(84.6 \%)$ and said that English was the main language spoken at home $(181 / 188,96.3 \%)$. Other participants described their ethnicity as Mixed 4/188 (2.1\%); Pakistani, Indian, or Asian 13/188 (6.9\%); any other White background 2/188 (1.1\%); or Black 2/188 (1.1\%). The majority were unmarried 182/188 (96.8\%) and living in shared accommodation 122/188 (64.9\%). Most participants $139 / 188(73.9 \%)$ had not seen a health professional in the past 2 weeks. Of those that had, most had seen a general practitioner (family doctor; $n=26$ ) or a physiotherapist $(n=4)$.

\section{Materials}

\section{eHealth Literacy Scale (eHEALS)}

The eHEALS [16] is an 8-item measure of eHealth literacy, and has an internal consistency (Cronbach $\alpha$ ) of .88. An example question is "I know how to use the Internet to answer my questions about health." The responses range from 1 (strongly disagree) to 5 (strongly agree), with higher scores indicating a higher level of eHealth literacy.

\section{Newest Vital Sign (NVS)}

The NVS [22,23] is a measure of FHL, and has an internal consistency (Cronbach $\alpha$ ) of .70. It includes a maximum of 7 questions, in which participants answer questions (involving calculations) relating to the nutritional information label on a tub of ice cream. The responses to questions are scored as either correct or incorrect and range from 0 to 6 , with higher scores indicating higher levels of FHL.

\section{Need for Cognition Scale}

The Need for Cognition Scale [44] is an 18-item measure which assesses a tendency to enjoy and engage in effortful cognitive activity. It has an internal consistency (Cronbach $\alpha$ ) of .88, suggesting good reliability. An example question is "I really enjoy a task that involves coming up with new solutions to problems". Items are scored from -4 (very strong disagreement) to 4 (very strong agreement), with higher scores signaling greater NFC. 


\section{Irrational Health Belief Scale}

The Irrational Health Belief Scale [45] is a 20-item scale assessing the tendency to appraise health-related information in an irrational manner, and has an internal consistency (Cronbach $\alpha$ ) of .90. It includes a series of vignettes to which participants have to rate their perceived response from a 5-point scale ranging from 1 (Not at all like I would think) to 5 (Almost exactly like I would think). For example, "Your doctor recommends a new medication for an ongoing health problem and indicates that about $10 \%$ of patients experience unpleasant side effects from the medicine. You think to yourself, 'If anyone is going to have side effects, it's going to be me'.' Scores are summed, with higher scores relating to higher IHBs.

\section{General Self-Efficacy (GSE) Scale}

The General Self-Efficacy (GSE) [46] scale is a 10-item measure, which captures the extent to which individuals are optimistic about their ability to cope with challenging situations, and has an internal consistency (Cronbach $\alpha$ ) of .90. An example question is "I can always manage to solve difficult problems if I try hard enough." The measure has Likert scale scoring, with responses ranging from 1 (not at all true) to 4 (exactly true). The answers are summed, with total scores ranging from 10 to 40. A higher score indicates greater SE.

\section{Procedure}

Ethical approval from the Leeds Beckett Psychology Ethics Committee was granted on December 12, 2017 (number: $\mathrm{PH} / \mathrm{AW}$ /121217). Participants took part in this study in order to generate data for them to analyze in a research methods module, and gave informed consent for these data to be used in further research. All measures were programmed into Qualtrics, a web-based survey tool, and participants completed these in-exam conditions during research methods sessions over the course of 1 week in March 2018.

\section{Data Analysis}

All data analyses were conducted using IBM SPSS Statistics (version 26). Internal consistency of the scales was examined using the Cronbach alpha coefficient. The psychometric properties of the eHEALS in a UK sample were explored using EFA. We initially examined correlations between all key variables. We had theoretical grounds to suggest that GSE would be a significant predictor of eHealth literacy, therefore a hierarchical multiple regression was performed by entering GSE first and then examining the impact of NFC, IHBs, NVS, and GSE on the outcome variable eHEALS. For the NVS, $18 \%$ of the data were missing, therefore mean scores were inputted; missing data were $<0.01 \%$ for other variables.

Data assumption tests were performed prior to conducting the linear regression, including Cook distance, collinearity, variance inflation factor, Durbin-Watson, and homoscedasticity. To test for normality, skewness and kurtosis values were computed prior to correlation analysis.

An EFA was used to examine the eHEALS structural validity on the 8 data item set $(\mathrm{N}=188$ cases $)$. The minimum recommended sample size to conduct an EFA is 100 [47] and if factors emerge with 4 or more loadings over 0.6, then this would be deemed reliable regardless of sample size [48]. In addition to the total variance explained, the scree plot, eigenvalues, and component loadings were assessed to verify the factor structure of the eHEALS in this population.

\section{Results}

Descriptive statistics for all key variables are presented in Table 1. All data met the requirements for parametric testing, with skewness and kurtosis values between +2.0 and -2.0 [49], with the exception of the NVS which was negatively skewed (as expected in an educated undergraduate sample). After a verbal consultation with a colleague (G. Rowlands, London South Bank University, personal communication), the decision was made not to transform the NVS data, as this has not been done using this measure before. Therefore, a Spearman nonparametric correlation coefficient $(\rho)$ was employed for the NVS, thus elsewhere the NVS results should be interpreted with caution.

Table 1. Descriptive statistics and internal consistency for key variables.

\begin{tabular}{llllc}
\hline Measure & $\mathrm{N}$ & Range & Mean (SD) & Cronbach $\alpha$ \\
\hline Electronic Health Literacy Scale & 188 & $12-40$ & $29.46(4.91)$ & .84 \\
Newest Vital Sign & 154 & $2-6$ & $5.44(0.94)$ & .60 \\
General Self-Efficacy Scale & 188 & $20-40$ & $29.78(3.84)$ & .80 \\
Irrational Health Belief Scale & 188 & $18-64$ & $31.30(9.12)$ & .85 \\
Need for Cognition Scale & 188 & $23-85$ & $7.02(18.97)$ & .90 \\
\hline
\end{tabular}

Correlations between key variables are presented in Table 2 . The main finding of interest is the significant positive correlation between eHEALS and GSE $(r=0.28, P<.001)$. No other significant relationships were noted between eHEALS and other key variables. The GSE and NFC scores were also positively correlated $(r=0.33, P<.001)$, and NFC and IHBs were significantly negatively correlated $(r=-0.14, P=.03)$. Using Spearman correlations, GSE and NVS $\left(r_{\mathrm{s}}=0.14, P=.04\right)$ and NFC and NVS $\left(r_{\mathrm{s}}=0.19, P=.003\right)$ were positively correlated. 
Table 2. Correlation coefficients for key variables ${ }^{\mathrm{a}}$.

\begin{tabular}{llllll}
\hline Measure & 1 & 2 & 3 & 4 & 5 \\
\hline 1. Electronic Health Literacy Scale & $-\mathrm{b}$ & 0.02 & $0.28^{\mathrm{c}}$ & -0.11 & -0.08 \\
2. Newest Vital Sign & 0.07 & - & 0.14 & $-0.14^{\mathrm{d}}$ & $0.20^{\mathrm{c}}$ \\
3. General Self-Efficacy Scale & $0.28^{\mathrm{c}}$ & 0.80 & - & $-0.33^{\mathrm{c}}$ \\
4. Irrational Health Belief Scale & -0.11 & $-0.18^{\mathrm{d}}$ & -0.14 & $-0.14^{\mathrm{d}}$ \\
5. Need for Cognition Scale & 0.11 & $0.19^{\mathrm{c}}$ & $0.33^{\mathrm{c}}$ & $-0.14^{\mathrm{d}}$ & - \\
\hline
\end{tabular}

\footnotetext{
${ }^{a}$ All correlations are Pearson with the exception of NVS where Spearman was performed.

${ }^{\mathrm{b}}$ Not applicable.

${ }^{\mathrm{c} C o r r e l a t i o n}$ is significant at the 0.01 level.

${ }^{\mathrm{d}}$ Correlation is significant at the 0.05 level.
}

All assumptions of the regression analysis were met, and a hierarchical procedure was performed to assess if the variables GSE, NVS, IHB, and NFC could predict eHealth literacy measured by the eHEALS. GSE was entered first into the model (Model 1) and this explained a significant proportion $(8.0 \%)$ of the variance in eHealth literacy $\left(F_{1,186}=16.16, P<.001, R^{2}=0.08\right)$. Model 2 (including GSE, NFC, IHB, and NVS) explained a nonsignificant $0.6 \%$ increase in the variance $\left(F_{4,183}=4.30, P=.80\right.$, $\left.R^{2}=0.086\right)$. Together, both models explained $8.6 \%$ of the total variance. Table 3 shows that only GSE was a significant predictor in each model. The internal consistency of most scales was good (ie, $\leq 0.80$ ), excluding the NVS, for which this was 0.60 .

Table 3. Beta coefficients, standard errors (SEs), standardized betas, and significance value for each model and predictors therein.

\begin{tabular}{|c|c|c|c|c|}
\hline Factors & $\beta$ coefficient & SE $\beta$ & Standardized $\beta$ & $P$ \\
\hline Constant & 18.71 & 2.70 & $-^{\mathrm{a}}$ & $<.001$ \\
\hline General self-efficacy (Model 1) & 0.36 & 0.90 & .28 & $<.001^{\mathrm{b}}$ \\
\hline Constant & 20.84 & 3.71 & - & $<.001$ \\
\hline General self-efficacy (Model 2) & 0.34 & 0.09 & .27 & $<.001^{\mathrm{b}}$ \\
\hline Need for Cognition & 0.00 & 0.02 & .00 & .93 \\
\hline Irrational Health Beliefs & -0.04 & 0.03 & -.08 & .28 \\
\hline Newest Vital Sign & -0.07 & 0.32 & -.01 & .83 \\
\hline
\end{tabular}

${ }^{\mathrm{a}}$ Not applicable.

${ }^{\mathrm{b}}$ Significant at the 0.01 level.

Using principal axis factoring an EFA was conducted on the 8 items with varimax rotation. The Kaiser-Meyer-Olkin measure verified sampling adequacy at 0.80 above the minimum criterion of 0.50, and all Kaiser-Meyer-Olkin values for individual items were 0.65 or more. The Bartlett test of sphericity was also significant at $P<.001$. All items on the eHEALS correlated significantly at $P=.001$. A determinant value of 0.023 , which is greater than the required value (ie, >0.00001), revealing collinearity levels, was not detrimental to the analysis, and thus, no items were removed.

The eHEALS performed well in terms of psychometrics in this sample (Table 4): we calculated a Cronbach $\alpha$ value of .84 for the total eHEALS score, whereas for factors 1 and 2 this was .90 and .77 , respectively, but when removing item 8 , which had a coefficient of less than 4 , the Cronbach $\alpha$ for factor 2 increased to .80 . However, almost one-third scored the maximum on the eHEALS overall (Table 4).

Table 4. Descriptive statistics, floor, and ceiling effects for eHEALS ${ }^{\mathrm{a}}$ overall and its factors 1 and 2.

\begin{tabular}{llll}
\hline Measure & Mean (SD) & Floor effect (\% of min score) & Ceiling effects $(\%$ max score) \\
\hline eHEALS & $29.46(4.91)$ & 16.48 & 28.12 \\
Factor 1: Information acquisition & $11.46(0.80)$ & 2.65 & 10.11 \\
$\quad$ Factor 2: Information application & $19.07(1.00)$ & 13.82 & 17.70 \\
\hline
\end{tabular}

\footnotetext{
aeHEALS: Electronic Health Literacy Scale.
} 
The scree plot confirmed that two factors had Eigen values over the Kaiser criterion of 1 and together explained $64.6 \%$ of the variance. Table 5 shows the results of the EFA, suggesting that factor 1 (items 1-3) represents information acquisition and factor 2 (4-8) information application.

Table 5. Summary of the exploratory factor analysis on the eHEALS ${ }^{\text {a }}$.

\begin{tabular}{lcc}
\hline Items on the eHEALS & Factor 1 (acquisition) & Factor 2 (application) \\
\hline 1. I know where to find helpful health resources on the Internet & .91 & .78 \\
2. I know how to find helpful health resources on the Internet & .72 & .74 \\
3. I know what health resources are available on the Internet & .63 \\
4. I know how to use the health information I find on the Internet to help me & .63 \\
5. I know how to use the Internet to answer my questions about health & .62 \\
6. I feel confident in using information from the Internet to make health decisions & .32 \\
7. I have the skills I need to evaluate the health resources I find on the Internet & 1.2 \\
8. I can tell high quality health resources from low quality health resources on the Internet & 4.0 & 15.1 \\
Eigen values & 49.4 & \\
Percentage of variance & & .32 \\
\hline
\end{tabular}

a eHEALS: Electronic Health Literacy Scale.

\section{Discussion}

\section{Principal Findings}

In this exploratory study we have been the first to investigate relationships and potential predictors of key variables influencing eHealth literacy sample of UK University students. A highly significant positive relationship was found between eHEALS and GSE scores, but eHealth literacy did not significantly correlate with any other factor. However, significant positive correlations between NFC and the NVS, and between NFC and GSE were demonstrated as well as a significant negative association between NFC and IHB. Our secondary aim was to explore the underlying construct of the eHEALS in a UK TYA sample using EFA, where we found 2 underlying factors within the scale related to information acquisition and information application.

Despite the expected negatively skewed distribution indicating higher scores on the NVS in our student sample, FHL measured by the NVS was not found to be a significant predictor of eHealth literacy. Previously Del Giudice and colleagues [21] demonstrated large associations between functional and eHealth literacy; however, in their study, FHL was not directly measured but rather assumed (as a proxy measure) based on studying or working in the health sector (eg, physicians, nurses, and allied health professions). Further, Del Giudice et al [21] found that for older and better educated participants eHEALS scores were higher. Our sample comprised psychology students (a health-focused subject), but perhaps the younger age of our sample (mean age 20) could have been an influencing factor in the lack of significant association with the eHEALS scores.

In line with the literature, those who scored highly in our sample on the NVS (a test of functional literacy) also scored highly on the NFC scale. This suggests an overlap between these 2 variables in that someone who prefers effortful cognitive activity would be more likely to score highly on a functional literacy test [26]. Our findings do not support the health literacy aspect of the Lily model in terms of demonstrating a relationship between functional and eHealth literacy. However, the expected negatively skewed scores in this educated sample and the internal consistency of .60 of this scale would suggest proceeding with caution in interpretation of our findings. In future studies it may be useful to explore FHL with the NVS in a more diverse population of young people who are either unemployed or who have not had a university education, as there is an urgent need to explore the factors driving FHL in all young people [50] to enable successful health promotion strategies.

The significant negative association between NFC and IHBs was as predicted, as IHBs are usually strongly held and people displaying IHBs have a limited need or desire to acquire new information to challenge or inform these beliefs [32]. Although counterintuitively, this did not transfer into a tangible negative association with eHealth literacy.

\section{Self-Efficacy}

SE has been shown to be a pivotal component in the adoption and execution of healthy behaviors [51], and that it being a significant predictor of eHealth literacy would seem entirely plausible. Previously, internet SE was deemed to play a key role in the process of using the internet to acquire health information [52]. With this in mind it may be useful to explore the relationship between eHealth literacy and a measure of health-related SE (eg, [53]). Using a dedicated health SE measure may have accounted for more variance in the model and therefore may be a greater predictor. Interestingly, others have argued that the eHEALS actually measures SE rather than eHealth literacy [29]; indeed, the question prefixes (eg, "I know how to" and "I have the skills to") would seem to tap into confidence and SE rather than assess performance. Perhaps, implementation of internet skills could not be predicted from high eHEALS scores, suggesting an incongruence between 
perceived and actual eHealth literacy [54]. We echo the thoughts of Britt and Hatten [29] who call for the relationship between SE and eHealth literacy to be fully explored.

\section{Need for Cognition}

We found a lack of significant correlation and predictive impact of NFC on the outcome variable (eHEALS) in contrast to the US study of young university students in which an association between the 2 variables was demonstrated [29]. It is useful to try to explain the reasons for failure to replicate these findings in a UK sample. The mean eHEALS scores and standard deviations were very similar in this study and the one conducted in the United States [29], and both samples were of a similar age. However, the US study had a larger sample yielding greater power to detect significant associations. Moreover, our UK sample produced higher NFC scores than participants in the US study, but the latter did not provide information on the types of courses the students were enrolled in. Conceivably, the type of course influenced the results, as Del Giudice and colleagues [21] found that participants' exposure to health-related study was associated with higher eHealth literacy scores.

\section{Scale Structure}

Previously the eHEALS was thought to be a unidimensional scale [16,17]; however, in the UK a confirmatory factor analysis and structured equation modeling in a large study with baby boomers in the United States, UK, and New Zealand (born between 1946 and 1954) found the eHEALS to have 3 distinct scales related to the Lily model [43]. They found items 1 and 2 related to awareness, items 3-5 related to skills to access resources, and items 6-8 evaluation of resources (self-efficacy). The authors recognize that more work needs to be done, particularly in other age groups to verify the 3 -factor structure. Our findings that the eHEALS related to 2 distinct constructs, namely, information acquisition (items 1-3) and information application (items 4-8), concur with those of Soellner et al [55], who found the 2-factor structure to be more compelling than a single one. However, we would recommend continuing to explore the construct validity of the scale in different populations.

\section{Limitations}

This was a cross-sectional design and as such only measured eHealth literacy at one time point, although it may be more revealing to measure this longitudinally to explore temporal changes and responses to changing circumstance (eg, an individual's own health concerns). The skewed distribution of the NVS data and low internal consistency ensure that we proceed with caution and thus cannot conclusively state that FHL does not influence eHealth literacy in a UK TYA population. However, we also must question "Does perceived
eHealth literacy (as measured by the eHEALS) translate into competent performance on the internet to gain health information?" Others have also found that the expected strong positive relationships between eHEALS scores and internet performance were absent [53]. This suggests that future studies should also focus on measuring practical internet tasks along with perceived eHealth literacy as a comprehensive measurement of true eHealth literacy.

In this study, because GSE only accounted for a small proportion of variance in our predictive model, we must speculate that alternative, more potent predictors of eHealth literacy exist. Gilstad [56] has proposed further aspects to eHealth literacy, thereby expanding the Lily model proposed by Norman and Skinner [11]. Four additional aspects to the Lily model were proposed: bodily experience, procedural literacy, contextual and cultural literacy, and communicative expertise. These additional factors are particularly pertinent to young people as they navigate seeking health information online, particularly knowledge of the norms, values, rules, and regulations in social situations (contextual and cultural literacy) and bodily experience (the ability to identify a health problem in one's own body). A recent work [57] demonstrated that delayed help seeking for potential breast cancer in females was associated with dissatisfaction with their breasts. Given that body dissatisfaction increases for both males and females as they transition to young adulthood [58], it would be interesting to explore whether body dissatisfaction could impact on their eHealth literacy.

\section{Conclusion}

We are reassured that NHS England [59] is working toward improving health literacy to reduce health inequalities, and perhaps there should be a greater directive to expand this initiative to include eHealth literacy. eHealth literacy should not be seen as a static state, but rather as a dynamic evolving skill set that will develop over time and in response to individual need and circumstance [11]. This would seem a logical step forward to serve digitally native young people as these are the generation that will "Google it" for health information into adulthood.

In conclusion, this is the first study in the UK to explore relationships between these key variables in a TYA population, and to perform EFA on the eHEALS with a TYA sample in the UK. As such, we can confirm the stability of the scale. The findings that SE has a major influence on eHealth literacy should consolidate its status as underpinning the Lily model, and as a fundamental starting point from where eHealth literacy is developed and understood. Future studies will explore physical and mental health status, health SE, and body image as potential predictors of eHealth literacy in more diverse TYA populations.

\section{Conflicts of Interest}

None declared.

\section{References}

1. Office of National Statistics UK. Internet Users, UK: 2018. URL: https://www.ons.gov.uk/businessindustryandtrade/ itandinternetindustry/bulletins/internetusers/2018 [accessed 2019-04-19] 
2. Campbell D. British teenagers among world's most extreme internet users, report says. The Guardian. 2017 Jun 30. URL: https://www.theguardian.com/technology/2017/jun/30/ british-teenagers-among-worlds-most-extreme-internet-users-report-says [accessed 2019-04-19]

3. Park E, Kwon M. Health-Related Internet Use by Children and Adolescents: Systematic Review. J Med Internet Res 2018 Apr 03;20(4):e120 [FREE Full text] [doi: 10.2196/jmir.7731] [Medline: 29615385]

4. Beck F, Richard J, Nguyen-Thanh V, Montagni I, Parizot I, Renahy E. Use of the internet as a health information resource among French young adults: results from a nationally representative survey. J Med Internet Res 2014;16(5):e128 [FREE Full text] [doi: 10.2196/jmir.2934] [Medline: 24824164]

5. Haluza D, Naszay M, Stockinger A, Jungwirth D. Digital Natives Versus Digital Immigrants: Influence of Online Health Information Seeking on the Doctor-Patient Relationship. Health Commun 2017 Nov;32(11):1342-1349. [doi:

10.1080/10410236.2016.1220044] [Medline: 27710132]

6. Purcell GP, Wilson P, Delamothe T. The quality of health information on the internet. BMJ 2002 Mar 9;324(7337):557-558 [FREE Full text] [Medline: 11884303]

7. Eysenbach G, Powell J, Kuss O, Sa E. Empirical studies assessing the quality of health information for consumers on the world wide web: a systematic review. JAMA 2002;287(20):2691-2700. [doi: 10.1001/jama.287.20.2691] [Medline: 12020305]

8. Nutbeam D, Kickbusch I. Advancing health literacy: a global challenge for the 21st century. Health Prom Int 2000;5(3):183-184. [doi: 10.1093/heapro/15.3.183]

9. National Literacy Trust. Adults Literacy. URL: https://literacytrust.org.uk/parents-and-families/adult-literacy/ [accessed 2019-04-19]

10. National Center for Education Statistics. Fast Facts: Adult literacy. URL: https://nces.ed.gov/fastfacts/display.asp?id=69 [accessed 2019-04-19] [WebCite Cache ID https://nces.ed.gov/fastfacts/display.asp?id=69]

11. Norman CD, Skinner HA. eHealth Literacy: Essential Skills for Consumer Health in a Networked World. J Med Internet Res 2006 Jun;8(2):e9 [FREE Full text] [doi: 10.2196/jmir.8.2.e9] [Medline: 16867972]

12. Gray NJ, Klein JD, Noyce PR, Sesselberg TS, Cantrill JA. The Internet: a window on adolescent health literacy. J Adolesc Health 2005 Sep;37(3):243. [doi: 10.1016/j.jadohealth.2004.08.023] [Medline: 16109345]

13. Selwyn N. The digital native - myth and reality. AP 2009 Jul 05;61(4):364-379. [doi: 10.1108/00012530910973776]

14. Eysenbach G. Infodemiology: The epidemiology of (mis)information. Am J Med 2002 Dec 15;113(9):763-765. [doi: 10.1016/s0002-9343(02)01473-0] [Medline: 12517369]

15. Cline RJ, Haynes KM. Consumer health information seeking on the Internet: the state of the art. Health Educ Res 2001 Dec;16(6):671-692. [doi: 10.1093/her/16.6.671] [Medline: 11780707]

16. Norman CD, Skinner HA. eHEALS: The eHealth Literacy Scale. J Med Internet Res 2006 Nov;8(4):e27 [FREE Full text] [doi: 10.2196/jmir.8.4.e27] [Medline: 17213046]

17. Nguyen J, Moorhouse M, Curbow B, Christie J, Walsh-Childers K, Islam S. Construct Validity of the eHealth Literacy Scale (eHEALS) Among Two Adult Populations: A Rasch Analysis. JMIR Public Health Surveill 2016 May;2(1):e24 [FREE Full text] [doi: 10.2196/publichealth.4967] [Medline: 27244771]

18. Paramio Pérez G, Almagro BJ, Hernando Gómez Á, Aguaded Gómez JI. [Validation of the eHealth Literacy Scale (eHEALS) in Spanish University Students]. Rev Esp Salud Publica 2015;89(3):329-338 [FREE Full text] [doi: 10.4321/S1135-57272015000300010] [Medline: 26388346]

19. Ma Z, Wu M. The Psychometric Properties of the Chinese eHealth Literacy Scale (C-eHEALS) in a Chinese Rural Population: Cross-Sectional Validation Study. J Med Internet Res 2019 Oct 22;21(10):e15720-e15736 [FREE Full text] [doi: 10.2196/15720] [Medline: 31642811$]$

20. Chang A, Schulz PJ. The Measurements and an Elaborated Understanding of Chinese eHealth Literacy (C-eHEALS) in Chronic Patients in China. Int J Environ Res Public Health 2018 Dec 23;15(7). [doi: 10.3390/ijerph15071553] [Medline: $\underline{30041420]}$

21. Del Giudice P, Bravo G, Poletto M, De Odorico A, Conte A, Brunelli L, et al. Correlation Between eHealth Literacy and Health Literacy Using the eHealth Literacy Scale and Real-Life Experiences in the Health Sector as a Proxy Measure of Functional Health Literacy: Cross-Sectional Web-Based Survey. J Med Internet Res 2018 Oct 31;20(10):e281 [FREE Full text] [doi: 10.2196/jmir.9401] [Medline: 30381283]

22. von WC, Knight K, Steptoe A, Wardle J. Functional health literacy and health-promoting behaviour in a national sample of British adults. J Epidemiol Community Health 2007 Dec;61(12):1086-1090 [FREE Full text] [doi:

10.1136/jech.2006.053967] [Medline: 18000132]

23. Rowlands G, Khazaezadeh N, Oteng-Ntim E, Seed P, Barr S, Weiss BD. Development and validation of a measure of health literacy in the UK: the newest vital sign. BMC Public Health 2013 Feb 07;13:116 [FREE Full text] [doi: 10.1186/1471-2458-13-116] [Medline: 23391329]

24. Feuerstein M. Media Literacy in Support of Critical Thinking. Journal of Educational Media 1999 Mar;24(1):43-54. [doi: $10.1080 / 1358165990240104]$

25. Cacioppo JT, Petty RE. The need for cognition. J Personality Soc Psych 1982 Jan;42(1):116-131. [doi: 10.1037/0022-3514.42.1.116] 
26. Cacioppo JT, Petty RE, Feng Kao C. The Efficient Assessment of Need for Cognition. Journal of Personality Assessment 2010 Jun 10;48(3):306-307. [doi: $10.1207 /$ s 15327752jpa4803 13]

27. Tuten TL, Bosnjak M. Understanding differences in web usage: the role of need for cognition and the five factor model of personality. Soc Behav Pers 2001 Jan 01;29(4):391-398. [doi: 10.2224/sbp.2001.29.4.391]

28. Williams-Piehota P, Schneider TR, Pizarro J, Mowad L, Salovey P. Matching health messages to information-processing styles: need for cognition and mammography utilization. Health Commun 2003 Oct;15(4):375-392. [doi:

10.1207/S15327027HC1504_01] [Medline: 14527864]

29. Britt RK, Hatten KN. Need for Cognition and Electronic Health Literacy and Subsequent Information Seeking Behaviors Among University Undergraduate Students. SAGE Open 2013 Oct 29;3(4):215824401350895. [doi: $10.1177 / 2158244013508957]$

30. Salkovskis PM, Warwick HM. Morbid preoccupations, health anxiety and reassurance: a cognitive-behavioural approach to hypochondriasis. Behav Res Ther 1986;24(5):597-602. [doi: 10.1016/0005-7967(86)90041-0] [Medline: $\underline{3753387]}$

31. Warwick HM, Salkovskis PM. Hypochondriasis. Behav Res Ther 1990;28(2):105-117. [doi: 10.1016/0005-7967(90)90023-c] [Medline: 2183757]

32. Fulton JJ, Marcus DK, Merkey T. Irrational health beliefs and health anxiety. J Clin Psychol 2011 Jun;67(6):527-538. [doi: 10.1002/jclp.20769] [Medline: 21484800]

33. Goldberg JH, Halpern-Felsher BL, Millstein SG. Beyond invulnerability: the importance of benefits in adolescents' decision to drink alcohol. Health Psychol 2002 Sep;21(5):477-484. [doi: 10.1037//0278-6133.21.5.477] [Medline: 12211515]

34. Marcus DK, Gurley JR, Marchi MM, Bauer C. Cognitive and perceptual variables in hypochondriasis and health anxiety: a systematic review. Clin Psychol Rev 2007 Mar;27(2):127-139. [doi: 10.1016/j.cpr.2006.09.003] [Medline: 17084495]

35. Anderson DR, Emery CF. Irrational health beliefs predict adherence to cardiac rehabilitation: a pilot study. Health Psychol 2014 Dec;33(12):1614-1617. [doi: 10.1037/hea0000017] [Medline: 24490644]

36. Eastin MS, Guinsler NM. Worried and Wired: Effects of Health Anxiety on Information-Seeking and Health Care Utilization Behaviors. Cyber Psychol Behav 2006 Aug;9(4):494-498. [doi: 10.1089/cpb.2006.9.494]

37. Bandura A. Social foundations of thought and action: A social cognitive theory. New Jersey: Prentice Hall; Oct 1985.

38. Bandura A. The Explanatory and Predictive Scope of Self-Efficacy Theory. Journal of Social and Clinical Psychology 1986 Sep;4(3):359-373. [doi: 10.1521/jscp.1986.4.3.359]

39. Wood R, Bandura A. Impact of conceptions of ability on self-regulatory mechanisms and complex decision making. Journal of Personality and Social Psychology 1989;56(3):407-415. [doi: 10.1037/0022-3514.56.3.407]

40. Bandura A. Self-efficacy mechanism in physiological activationhealth-promoting behavior. In J. Madden, IV (Ed. ) 1991 ;229. [doi: 10.4135/9781412952576.n182]

41. Conner M. In: Norman P, editor. Predicting Health Behaviour: Research and Practice with Social Cognition Models. Maidenhead, Berkshire, United Kingdom: Open University Press; 1995.

42. Turan N, Kaya N, Aydın GO. Health Problems and Help Seeking Behavior at the Internet. Procedia - Social and Behavioral Sciences 2015 Jul;195:1679-1682. [doi: 10.1016/j.sbspro.2015.06.248]

43. Sudbury-Riley L, FitzPatrick M, Schulz PJ. Exploring the Measurement Properties of the eHealth Literacy Scale (eHEALS) Among Baby Boomers: A Multinational Test of Measurement Invariance. J Med Internet Res 2017 Dec 27;19(2):e53. [doi: 10.2196/jmir.5998] [Medline: 28242590]

44. Cacioppo JT, Petty RE, Feng Kao C. The Efficient Assessment of Need for Cognition. Journal of Personality Assessment 2010 Jun 10;48(3):306-307. [doi: 10.1207/s15327752jpa4803_13]

45. Christensen AJ, Moran PJ, Wiebe JS. Assessment of irrational health beliefs: relation to health practices and medical regimen adherence. Health Psychol 1999 Mar;18(2):169-176. [doi: 10.1037//0278-6133.18.2.169] [Medline: 10194052]

46. Schwarzer R, Jerusalem M. Generalized Self-Efficacy scale. In: Weinman J, Wright S, Johnston M, editors. Measures in health psychology: A user's portfolio. Causal and control beliefs. Windsor: NFER - Nelson; 1995:35-37.

47. MacCallum RC, Widaman KF, Zhang S, Hong S. Sample size in factor analysis. Psychological Methods 1999;4(1):84-99. [doi: 10.1037/1082-989x.4.1.84]

48. Guadagnoli E, Velicer WF. Relation of sample size to the stability of component patterns. Psychological Bulletin 1988 Mar;103(2):265-275. [doi: 10.1037/0033-2909.103.2.265]

49. Gravetter F, Wallnau L. Essentials of Statistics for the Behavioral Sciences 8th Edition. Belmont, California, USA: Wadsworth; 2014.

50. Bröder J, Okan O, Bauer U, Bruland D, Schlupp S, Bollweg TM, et al. Health literacy in childhood and youth: a systematic review of definitions and models. BMC Public Health 2017 Apr 26;17(1):361 [FREE Full text] [doi: 10.1186/s12889-017-4267-y] [Medline: 28441934]

51. Schwarzer R, Fuchs R. Changing risk behaviors adopting health behaviors: The role of self-efficacy beliefs. In: Bandura A, editor. Self-efficacy in changing societies. New York USA: Cambridge University Press; 1995:259-288.

52. Hong T. The Internet and Tobacco Cessation: The Roles of Internet Self-Efficacy and Search Task on the Information-Seeking Process. J Comp Mediated Comm 2006 Jan;11(2):536-556. [doi: 10.1111/j.1083-6101.2006.00026.x]

53. Becker H, Stuifbergen A, Oh H, Hall S. Self-rated abilities for health practices: A health self-efficacy measure. Health Values: The Journal of Health Behavior, Education \& Promotion 1993;17(5):42-50. 
54. van de Vaart R, van Deursen AJ, Drossaert CH, Taal E, van Dijk JA, van de Laar MA. Does the eHealth Literacy Scale (eHEALS) measure what it intends to measure? Validation of a Dutch version of the eHEALS in two adult populations. J Med Internet Res 2011;13(4):e86 [FREE Full text] [doi: 10.2196/jmir.1840] [Medline: 22071338]

55. Soellner R, Huber S, Reder M. The Concept of eHealth Literacy and Its Measurement. Journal of Media Psychology 2014 Jan;26(1):29-38. [doi: 10.1027/1864-1105/a000104]

56. Gilstad H. Toward a Comprehensive Model of eHealth Literacy. 2014 May 19 Presented at: Proceedings of the 2nd European Workshop on Practical Aspects of Health Informatics; May 19, 2014; Trondheim Norway p. 1-10 URL: http://ceur-ws.org/ Vol-1251/paper7.pdf

57. Swami V, Furnham A. Breast size dissatisfaction, but not body dissatisfaction, is associated with breast self-examination frequency and breast change detection in British women. Body Image 2018 Mar;24:76-81. [doi: 10.1016/j.bodyim.2017.12.004] [Medline: 29304438]

58. Bucchianeri MM, Arikian AJ, Hannan PJ, Eisenberg ME, Neumark-Sztainer D. Body dissatisfaction from adolescence to young adulthood: findings from a 10-year longitudinal study. Body Image 2013 Jan;10(1):1-7 [FREE Full text] [doi: 10.1016/j.bodyim.2012.09.001] [Medline: 23084464]

59. NHS England. Up to 100,000 people use the internet to improve their health. 2013 Mar 13. URL: https://www.england.nhs.uk/ 2013/03/internet-health/ [accessed 2019-04-19]

\section{Abbreviations}

EFA: exploratory factor analysis

eHEALS: Electronic Health Literacy Scale

FHL: functional health literacy

GSE: general self-efficacy

IHB: irrational health belief

NFC: need for cognition

NVS: Newest Vital Sign

SE: self-efficacy

TOFHLA: Test of Functional Health Literacy in Adults

TYAs: teenagers and young adults

Edited by G Eysenbach; submitted 04.05.19; peer-reviewed by S Brudvig, G Bravo; comments to author 16.12.19; revised version
received 06.05.20; accepted 14.06.20; published 08.09.20
Please cite as:
Holch P, Marwood JR
EHealth Literacy in UK Teenagers and Young Adults: Exploration of Predictors and Factor Structure of the eHealth Literacy Scale
(eHEALS)
JMIR Form Res 2020;4(9):e14450
URL: $\underline{\text { http://formative.jmir.org/2020/9/e14450/ }}$
doi: $10.2196 / 14450$
PMID: $\underline{32897230}$

CPatricia Holch, Jordan R Marwood. Originally published in JMIR Formative Research (http://formative.jmir.org), 08.09.2020. This is an open-access article distributed under the terms of the Creative Commons Attribution License (https://creativecommons.org/licenses/by/4.0/), which permits unrestricted use, distribution, and reproduction in any medium, provided the original work, first published in JMIR Formative Research, is properly cited. The complete bibliographic information, a link to the original publication on http://formative.jmir.org, as well as this copyright and license information must be included. 